\title{
Survival analysis of multiple myeloma patients after autologous stem cell transplantation
}

\author{
Ju Li, Yan Zhu \\ Department of Hematology, Southwest Hospital, Army Medical University, Chongqing 400038, China \\ Contributions: (I) Conception and design: All authors; (II) Administrative support: All authors; (III) Provision of study materials or patients: All authors; \\ (IV) Collection and assembly of data: All authors; (V) Data analysis and interpretation: All authors; (VI) Manuscript writing: All authors; (VII) Final \\ approval of manuscript: All authors. \\ Correspondence to: Yan Zhu. Department of Hematology, Southwest Hospital, Army Medical University, Chongqing 400038, China. \\ Email: yanzhu1977@126.com.
}

Background: Hematopoietic stem cell transplantation has been applied to treat the hematologic
malignancies since the 1980 s. However, allogenic transplantation has inherent complications such as graft-
versus-host disease and graft failure. Autologous transplantation has become more and more popular because
of its lower transplant-related mortality. This study was performed to analyze the possible prognostic factors
for myeloma patients post stem cell transplantation.
Methods: Patients' information was collected by history review and follow-up through the phone call.
Kaplan-Meier was used to exhibit overall survival (OS) and progression-free survival (PFS). Univariate
and multivariate analyses were performed using Cox proportional hazards model. A $\mathrm{P}<0.05$ is considered
statistically significant. Results: Thirty patients with multiple myeloma were included in this study, 7 of them died because of myeloma relapse and myeloma-associated complications. The average survival time was 29.8 months and the median follow-up was 25.1 months. The 1 -year OS and PFS were $93.3 \%$ and $90.0 \%$, respectively. Both the 3 -year OS and PFS were $76.7 \%$. In a variety of factors, improved renal function showed a good effect on the outcome of transplantation.

Conclusions: To prevent cancer relapse after autologous transplantation, it is of great significance to achieve a complete remission prior to the transplantation.

Keywords: Multiple myeloma; survival analysis; hematopoietic stem cell transplantation (HSCT); retrospective study

Received: 28 April 2019; Accepted: 08 October 2019; Published: 12 December 2019.

doi: $10.21037 /$ sci.2019.10.05

View this article at: http://dx.doi.org/10.21037/sci.2019.10.05

\section{Introduction}

Multiple myeloma is a type of malignant proliferative disorders. It develops when plasmocytes undergo genetic mutations due to a variety of factors (1). Conventional chemotherapy is favorably considered as a valid action to improve the clinical symptoms and survival rate of patients. Unfortunately, like other hematopoietic malignancies, multiple myeloma cannot be completely cured by conventional chemotherapies (2). Notably, hematopoietic stem cell transplantation (HSCT) has been applied to a number of hematopoietic diseases, including leukemia, lymphoma, and myeloma, as well as other solid tumors and non-malignant disorders for almost 60 years (3). Therein, allogeneic HSCT (Allo-HSCT) is a strong consideration for myeloma patients of a high-risk stage, however, its application is somehow limited due to its extremely high potential of transplant-related mortality (4). Alternatively, autologous HSCT (Auto-HSCT) is widely utilized to make a balance between the risks and benefits as its efficacy is 
superior to conventional chemotherapy and its safety is better than Allo-HSCT, despite that it has a high recurrence rate that cannot be ignored (5). In order to prevent the poor outcome of the HSCT treatment for multiple myeloma, researchers have attempted to identify significant prognostic factors which may be modified in the future (6-9). Herein, this is a retrospective study including patients with myeloma and analyzing patients' prognosis post transplantation to discover possible prognostic factors that affect the efficacy of transplantation and to make a guidance for future clinical work.

\section{Methods}

\section{Patients}

This study included 30 patients with multiple myeloma. Diagnosis was confirmed by bone marrow aspiration and biopsy. These patients were hospitalized and underwent autologous hematopoietic stem cell collection and transplantation at Southwest Hospital in Chongqing, China from January 2011 to December 2016. Data regarding patient's status of illness including prognosis and treatment history were extracted retrospectively from online medical records and collected by follow-up through phone call. Auto-HSCT was administered to subjects following several challenges of chemotherapy. Prior to the transplantation, each patient would obtain the identification of blood type. Biochemistry analyses were as follows: complete blood cell count, serum calcium level, hepatic panel, kidney function tests, and serum $\beta 2$-microglobulin level. Serum monoclonal immunoglobulins (M protein) prior to transplantation were also included in our analysis due to the importance of their clinical reference. Serial radiographic films were utilized to determine bone marrow lesions. Patients were staged according to the International Staging System (ISS) which was proposed in 2005 (10) and Durie-Salmon staging system which has been widely used since 1970s (11). Both methods were adopted in combination to predict the efficacy of Auto-HSCT. Notably, the source of HSCT was peripheral blood stem cells (Auto-PBSCT) in our study. Hematopoietic stem cells were collected from the arm vein of self-donor by blood components apheresis surgery and then subjected to examine the frequencies of CD $34^{+}$ cells and mononuclear cells by flow cytometric analysis. To ensure enough cells for transplantation, we required that $\mathrm{CD} 4^{+}$cells $\geq 2 \times 10^{6} / \mathrm{kg}$ and the mononuclear cell count $\geq 3 \times 10^{8} / \mathrm{kg}$ body weight of patients. All the transplantation procedures were performed in a special unit with highefficiency particulate air (HEPA) filtration. In order to minimize transplant-associated infectious complications, patients were not allowed to leave this unit until their peripheral blood neutrophil count was above $1.5 \times 10^{9} / \mathrm{L}$ with the absence of any other serious complications. In some cases, patients would undergo a second transplantation to consolidate its efficacy.

\section{Statistical analysis}

The primary endpoint of our analysis was overall survival (OS), which was defined as the time from Auto-HSCT to the death of any causes or the last follow-up. Another endpoint was progression-free survival (PFS) which was determined as the time from Auto-HSCT to the progression or death of any causes. Kaplan-Meier method was used for analyzing the OS and PFS (12). Univariate analysis and multivariate analysis of factors affecting survival were carried out with a Cox proportional hazards model and variables with $\mathrm{P}>0.1$ were excluded from the models. A value of $\mathrm{P}<0.05$ was considered statistically significant. Statistical analysis was performed using the SPSS version 19.0.

\section{Results}

\section{Characteristics of patients and myeloma}

This study included 30 patients with multiple myeloma treated by Auto-PBSCT. Table 1 lists the characteristics of patients and myeloma at baseline. Of these patients, the median age was 49.6 years (range, 39-73 years) and 16 cases were younger than 50 years old. According to the Durie-Salmon staging, we considered blood hemoglobin greater than $100 \mathrm{~g} / \mathrm{L}$ as normal, less than $85 \mathrm{~g} / \mathrm{L}$ as decreased, and serum calcium higher than $2.98 \mathrm{mmol} / \mathrm{L}$ as increased. Serum albumin less than $35 \mathrm{~g} / \mathrm{L}$ was considered as decreased. Elevated serum creatinine was defined as $84 \mu \mathrm{mol} / \mathrm{L}$ and blood urea nitrogen (BUN) more than $8.3 \mathrm{mmol} / \mathrm{L}$ was considered as increased. ISS and DurieSalmon staging system are shown in Tables 2,3 $(10,11)$.

\section{Transplantation outcome (Table 4)}

Chemotherapy of 2-8 courses were performed in these patients followed by the Auto-HSCT. Prior to the transplantation, more than $90 \%(\mathrm{n}=28)$ of the subjects had 
Table 1 Characteristics of patients and lymphoma at baseline

\begin{tabular}{|c|c|c|}
\hline Variables & No. patients & Percent \% \\
\hline \multicolumn{3}{|l|}{ Gender } \\
\hline Male & 22 & 73.3 \\
\hline Female & 8 & 26.7 \\
\hline \multicolumn{3}{|l|}{ Age (years) } \\
\hline Median (range) & 49.6 [39-73] & \\
\hline$<50$ & 16 & 53.3 \\
\hline$\geq 0$ & 14 & 46.7 \\
\hline \multicolumn{3}{|l|}{ Blood type } \\
\hline$A$ & 10 & 33.3 \\
\hline$B$ & 8 & 26.7 \\
\hline $\mathrm{O}$ & 9 & 30.0 \\
\hline$A B$ & 3 & 10.0 \\
\hline \multicolumn{3}{|l|}{ Hemoglobin } \\
\hline Normal & 5 & 16.7 \\
\hline decreased & 25 & 83.3 \\
\hline \multicolumn{3}{|l|}{ Serum calcium } \\
\hline Normal & 27 & 90.0 \\
\hline Elevated & 3 & 10.0 \\
\hline \multicolumn{3}{|l|}{$\beta 2$-macroglobulin } \\
\hline$<3.5 \mathrm{mg} / \mathrm{L}$ & 17 & 56.7 \\
\hline $3.5-5.5 \mathrm{mg} / \mathrm{L}$ & 8 & 26.7 \\
\hline$>5.5 \mathrm{mg} / \mathrm{L}$ & 5 & 16.7 \\
\hline \multicolumn{3}{|l|}{ M protein band } \\
\hline Negative & 27 & 90.0 \\
\hline Positive & 3 & 10.0 \\
\hline \multicolumn{3}{|l|}{ Serum albumin } \\
\hline Normal & 13 & 43.3 \\
\hline Decreased & 17 & 56.7 \\
\hline \multicolumn{3}{|l|}{ Serum creatinine } \\
\hline Normal & 27 & 90.0 \\
\hline Elevated & 3 & 10.0 \\
\hline \multicolumn{3}{|l|}{ BUN } \\
\hline Normal & 29 & 96.7 \\
\hline Elevated & 1 & 3.3 \\
\hline
\end{tabular}

Table 1 (continued)
Table 1 (continued)

\begin{tabular}{lcc}
\hline Variables & No. patients & Percent \% \\
\hline X-ray test & 13 & 43.3 \\
Normal or isolated osteolytic lesions & 17 & 56.7 \\
Multiple osteolytic lesions & & \\
ISS stage & 17 & 56.7 \\
I & 8 & 26.7 \\
II & 5 & 16.7 \\
III & & \\
Durie-Salmon stage & 2 & 6.7 \\
I & 11 & 36.7 \\
II & 17 & 56.7 \\
III & & \\
\hline BUN, blood urea nitrogen. & &
\end{tabular}

Table 2 ISS stage

\begin{tabular}{ll}
\hline Stage & Criteria \\
\hline I & $\beta 2$-macroglobulin $<3.5 \mathrm{mg} / \mathrm{L}$, albumin $>35 \mathrm{~g} / \mathrm{L}$ \\
II & Between I and III \\
III & $\beta 2$-macroglobulin $>5.5 \mathrm{mg} / \mathrm{L}$ \\
\hline ISS, International Staging System.
\end{tabular}

Table 3 Durie-Salmon stage

\begin{tabular}{ll}
\hline Stage & Criteria \\
\hline I & Meeting the followings: \\
& Hemoglobin $>100 \mathrm{~g} / \mathrm{L}$ \\
& Normal serum calcium \\
& X-ray test shows normal findings or isolated osteolytic \\
& lesions \\
& IgG $<50 \mathrm{~g} / \mathrm{L} ;$ IgA $<30 \mathrm{~g} / \mathrm{L} ;$ Bence-Jones proteins \\
& $<4 \mathrm{~g} / 24 \mathrm{~h}$ \\
& Between I and III \\
& Meeting one of the followings: \\
& Hemoglobin $<85 \mathrm{~g} / \mathrm{L}$ \\
II & Elevated serum calcium \\
& X-ray test shows multiple osteolytic lesions \\
& IgG $>70 \mathrm{~g} / \mathrm{L} ;$ IgA $>50 \mathrm{~g} / \mathrm{L} ;$ Bence-Jones proteins \\
& $>12$ g/24 $\mathrm{h}$
\end{tabular}


Table 4 Transplantation regimens and outcome

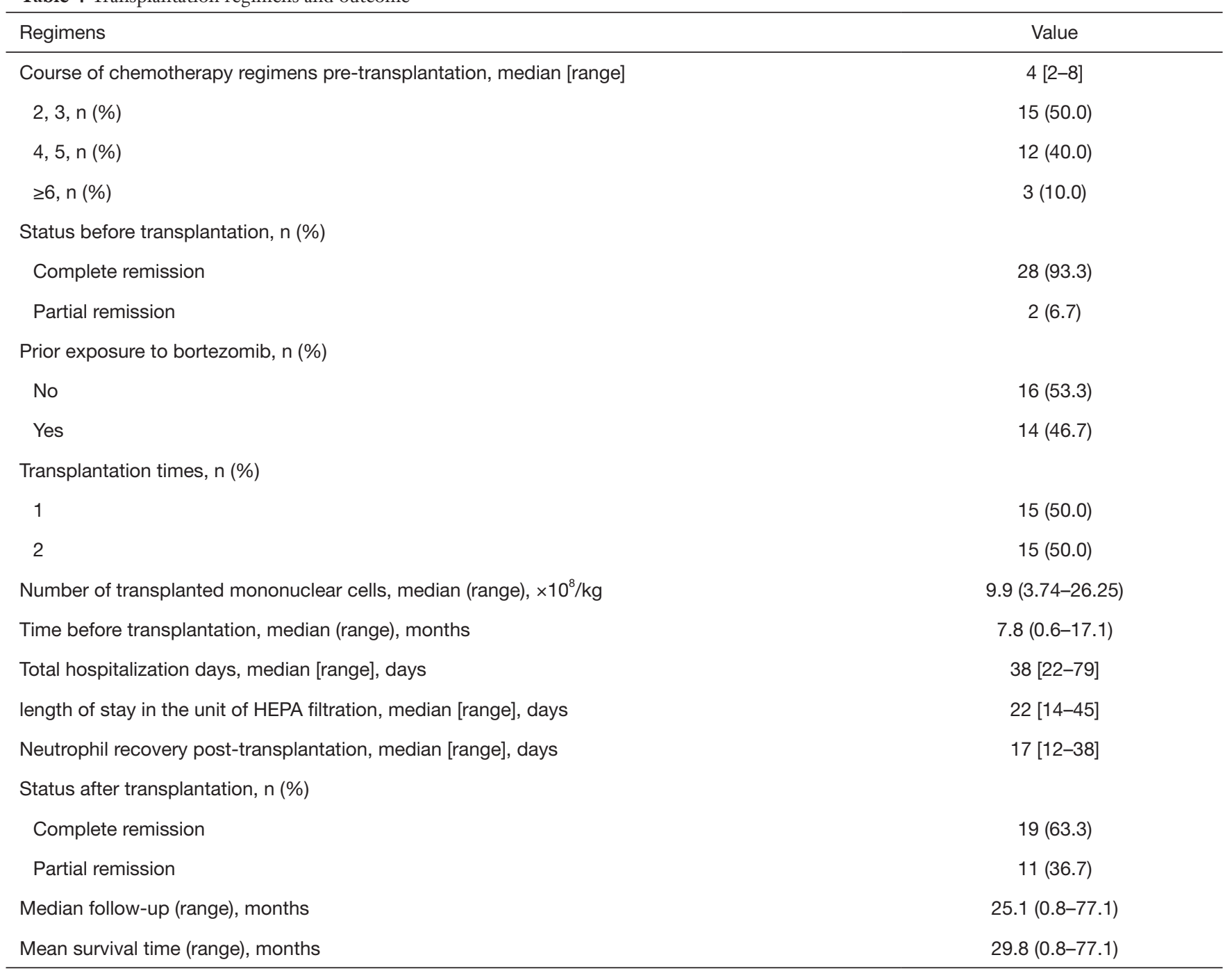

HEPA, high-efficiency particulate air.

achieved complete remission through chemotherapy. All the patients undergoing Auto-HSCT received a same type of conditioning regimen, i.e., melphalan $200 \mathrm{mg} / \mathrm{m}^{2}$, for the transplantation. Treatment responses were evaluated according to the National Comprehensive Cancer Network (NCCN) clinical practice guidelines in oncology for multiple myeloma (version 2017) (13). Over 60\% ( $\mathrm{n}=19)$ patients achieved complete remission after transplantation. After a median follow-up of 25.1 months, patients had an average survival time of 29.8 months after transplantation. Median survival time was not calculated because the mortality rate of patients did not account to $50 \%$.

\section{Survival analysis}

The median OS and PFS for the entire cohort have not been reached (Figures 1,2). The 1-year cumulative probabilities of OS and PFS were $93.3 \%$ and $90.0 \%$, respectively. Furthermore, the 3 -year PFS and OS were both equal to $76.7 \%$. Thus, only OS was used as the very endpoint in the univariate and multivariate analyses.

Results from univariate analysis of factors affecting OS are summarized in Table 5. Variable parameters, including gender, age, blood type, hemoglobin, serum calcium, $\mathrm{X}$-ray test, serum albumin, serum creatinine, BUN, $\beta 2$ - 


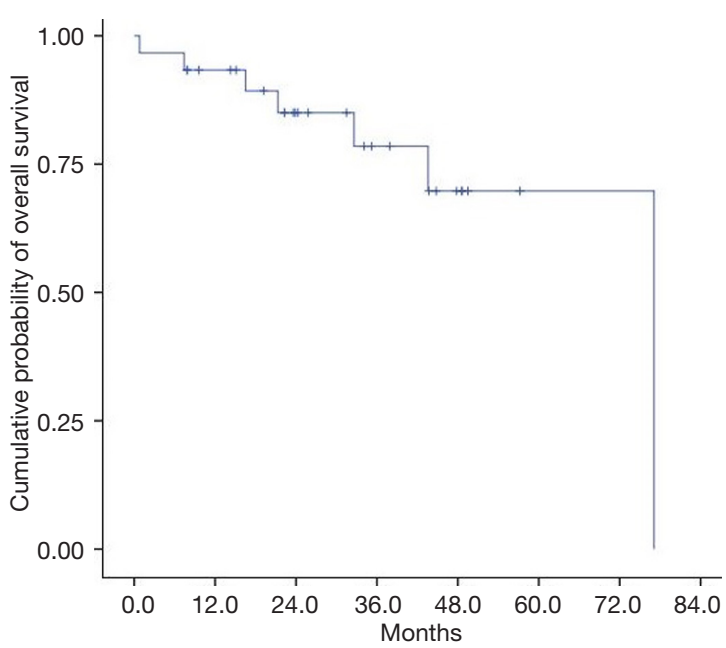

Figure 1 Kaplan-Meier method for estimation of overall survival in myeloma patients receiving Auto-HSCT. Auto-HSCT, autologous hematopoietic stem cell transplantation.

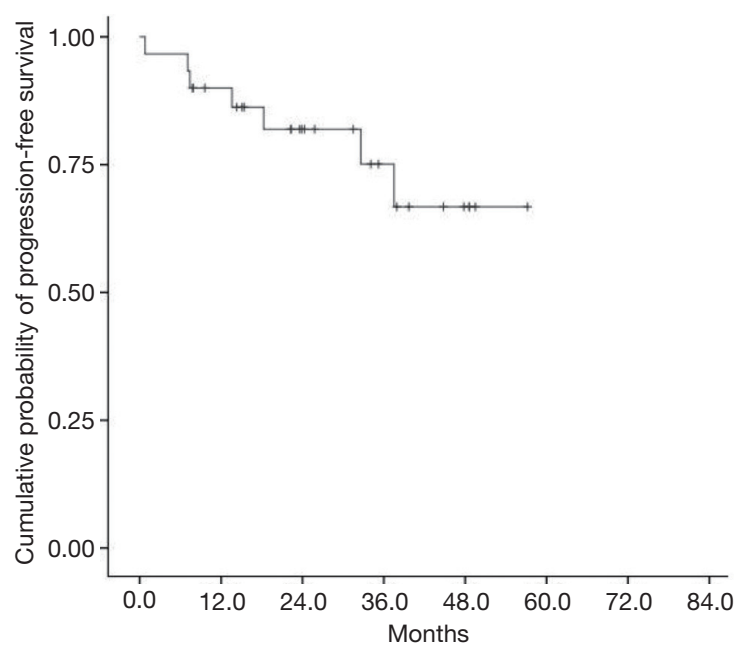

Figure 2 Kaplan-Meier method for estimation of progressionfree-survival in myeloma patients receiving Auto-HSCT. AutoHSCT, autologous hematopoietic stem cell transplantation.

Table 5 Univariate analysis of factors affecting OS in myeloma patients receiving Auto-HSCT

\begin{tabular}{|c|c|c|c|}
\hline Variables & HR & $95 \% \mathrm{Cl}$ & $P$ value \\
\hline Age & 0.573 & $0.100-3.160$ & 0.523 \\
\hline Blood type & 0.783 & $0.367-1.671$ & 0.527 \\
\hline Serum calcium & 5.101 & $0.929-28.01$ & 0.061 \\
\hline Serum albumin & 1.262 & $0.246-6.466$ & 0.780 \\
\hline Serum creatinine & 2.677 & $0.298-24.04$ & 0.379 \\
\hline$\beta 2$-macroglobulin & 1.804 & $0.643-5.061$ & 0.262 \\
\hline M protein band & 1.544 & $0.256-4.566$ & 0.183 \\
\hline Prior exposure to bortezomib & 0.446 & $0.076-2.605$ & 0.370 \\
\hline Times of chemotherapy before transplantation & 2.376 & $0.761-7.422$ & 0.136 \\
\hline Transplantation times & 0.423 & $0.077-2.313$ & 0.321 \\
\hline Course before transplant & 1.044 & $0.862-1.264$ & 0.659 \\
\hline Total hospitalization days & 0.981 & $0.921-1.044$ & 0.541 \\
\hline Days in the unit of HEPA filtration & 1.058 & $0.958-1.167$ & 0.265 \\
\hline Number of transplanted mononuclear cells & 1.055 & $0.908-1.225$ & 0.486 \\
\hline Neutrophil recovery post-transplantation & 1.235 & $0.226-6.761$ & 0.808 \\
\hline
\end{tabular}

OS, overall survival; Auto-HSCT, autologous hematopoietic stem cell transplantation; HR, hazard ratio; Cl, confidence interval; ISS, International Staging System; HEPA, high-efficiency particulate air. 
macroglobulin, M protein, ISS stage, Durie-Salmon stage, bortezomib addition, chemotherapy times pretransplantation, transplantation times, duration before transplantation, days in hospital and HEPA filtered unit, mononuclear cells number and neutrophil recovery were analyzed using Cox proportional hazards model. Statistical data of the above parameters failed to identify any factors of prognostic value for patients. Thus, multivariate analysis was not applicable.

\section{Discussion}

Although Auto-HSCT has been used to treat a variety of hematological malignancies, relapse and graft failure have been the biggest obstacles that affect the outcome of HSCT $(14,15)$. To investigate the potential factors resulting in an unfavorable prognosis, a large number of retrospective and prospective studies have been carried out which will contribute to providing valuable references for clinical work in the future (16-18). However, this topic regarding HSCT is far from being fully understood due to the significant heterogeneity between individual studies. Therefore, more investigations are still needed for this issue. With regard to multiple myeloma treated with HSCT, its profoundly unique characteristics such as impaired kidney function and abnormally produced antibodies may bring about more difficulties to the anticipation of HSCT-related outcomes $(19,20)$.

For the past 50 years, a combined chemotherapy of melphalan and prednisone has been the standard treatment for multiple myeloma. In recent years, addition of bortezomib has been reported to contribute to an improved prognosis of myeloma patients, studies showed that bortezomib-treated patients had a better life span than non-bortezomib-treated patients (21). Mechanically, bortezomib inhibits the $26 \mathrm{~S}$ proteasome and subsequently prevents the degradation of pro-apoptotic factors, triggering the cell death of myeloma cells $(22,23)$. Due to its dramatic effect, bortezomib is even suitable for patients with refractory or advanced disease $(21,24)$. In this study, sixteen patients had a history of bortezomib administration with one to six courses. However, statistical analysis showed that bortezomib application had no significant effect on prognosis in this study. We suppose that non-standard application of bortezomib may lead to a bias in the statistical results. Besides, it's necessary to determine patients' response to bortezomib prior to transplantation. Because the administration of bortezomib with various courses may not always be enough to reduce or eradicate the myeloma cells, downregulating abnormally produced myeloma protein. To resolve the above problems, a prospective randomized controlled trial can verify the efficacy of bortezomib and detection of myeloma protein in serum and urine using daratumumab immunofixation reflex assay is able to confirm the response of cancer cells to bortezomib (25). Several studies have revealed that age, gender, clinical stage, and neutrophil recovery after transplantation are closely related to the efficacy of transplantation, but these factors were not identified as predictors for patients' outcomes in our study (26-28). However, aged patients probably will experience a delayed neutrophil recovery post transplantation, showing some undesirable adverse effects such as fever and mild infections. Similar causalities can also be generated between other factors such as an advanced disease stage and a delayed neutrophil recovery by which may explain the outcome of disease. Unfortunately, no statistically significant evidence was shown. To apply Durie-Salmon stage to our study, hemoglobin, serum calcium, X-ray test findings, and serum monoclonal immunoglobulin were collected. Besides, we used $\beta 2$-microglobulin and serum albumin to determine ISS stage of a patient as well. Both stage systems work well to guide treatment at diagnosis, but it remains controversial of their prognostic value for myeloma patients post transplantation. For fair evaluation of ISS staging and Durie-Salmon staging, clinical practice may be more persuasive. What's more, available studies have found that elevated serum creatinine and BUN due to the renal impairment have adverse impact on the prognosis of patients $(29,30)$, which was steadily supported in our study. Only a few patients had an elevated serum creatinine $(n=3)$ or BUN ( $\mathrm{n}=1)$ in this study, this relatively low incidence could possibly explain the scarcity of endpoint events. Thus, it's suggestive to reverse the renal impairment prior to transplantation in order to improve the survival which is supported by other studies $(31,32)$. Our previous study also found prior chemotherapy regimens before transplantation, disease duration before transplantation, total hospitalization days, days in the unit of HEPA filtration, and number of transplanted mononuclear cells had no effect on the prognosis of patients, which was consistent with the results in this study (28). Considering that the most important factors affecting the efficacy of transplantation are disease subtypes and recovery after transplantation $(28,33)$, other factors may not be as crucial as the above two.

Compared to prospective studies, retrospective studies have inherent limitations that differences in disease 
subtypes and prior treatments may bias the results $(33,34)$. In addition, psychosocial factors, such as sentiments and personality characteristics, have the potential to affect the outcomes of Auto-HSCT patients, which was not investigated in our study (35-37). Inevitably, heterogeneity of the treatment history prior to transplantation is an important weakness of retrospective studies. To delve into the nature of multiple myeloma more deeply, we are concerned that several parameters which were not included here due to incomplete medical record should be collected in the future, such as immunoglobulin subtypes and the extend of bone/soft tissue involvement. Another limitation is the small sample size in the present study. Future studies with large sample size may improve our understanding of factors that can be used to predict the outcome of AutoHSCT patients.

\section{Conclusions}

Auto-HSCT can improve the survival of multiple myeloma. Improved health status before transplantation warrants a prolonged survival of myeloma patients after transplantation. Expanding the sample size, as well as extending period of follow-up, can improve the reliability of survival analysis and is of importance for us to explore the prognostic factors.

\section{Acknowledgments}

None.

\section{Footnote}

Conflicts of Interest: The authors have no conflicts of interest to declare.

Ethical Statement: The authors are accountable for all aspects of the work in ensuring that questions related to the accuracy or integrity of any part of the work are appropriately investigated and resolved.

\section{References}

1. Mehta GR, Suhail F, Haddad RY, et al. Multiple myeloma. Dis Mon 2014;60:483-8.

2. Weinhold N, Ashby C, Rasche L, et al. Clonal selection and double-hit events involving tumor suppressor genes underlie relapse in myeloma. Blood 2016;128:1735-44.
3. Passweg JR, Baldomero H, Bader P, et al. Hematopoietic stem cell transplantation in Europe 2014: more than 40000 transplants annually. Bone Marrow Transplant 2016;51:786-92.

4. Dhakal B, Vesole DH, Hari PN. Allogeneic stem cell transplantation for multiple myeloma: is there a future? Bone Marrow Transplant 2016;51:492-500.

5. Holstein SA, McCarthy PL. Improved survival with salvage autologous stem-cell transplantation in myeloma. Lancet Haematol 2016;3:e306-7.

6. Holstein SA, Jung SH, Richardson PG, et al. Updated analysis of CALGB (Alliance) 100104 assessing lenalidomide versus placebo maintenance after single autologous stem-cell transplantation for multiple myeloma: a randomised, double-blind, phase 3 trial. Lancet Haematol 2017;4:e431-42.

7. Merz M, Jansen L, Castro FA, et al. Survival of elderly patients with multiple myeloma-Effect of upfront autologous stem cell transplantation. Eur J Cancer 2016;62:1-8.

8. González-Calle V, Cerdá S, Labrador J, et al. Recovery of polyclonal immunoglobulins one year after autologous stem cell transplantation as a long-term predictor marker of progression and survival in multiple myeloma. Haematologica 2017;102:922-31.

9. Gay F, Oliva S, Petrucci MT, et al. Autologous transplant vs oral chemotherapy and lenalidomide in newly diagnosed young myeloma patients: a pooled analysis. Leukemia 2017;31:1727-34.

10. Greipp PR, San Miguel J, Durie BG, et al. International staging system for multiple myeloma. J Clin Oncol 2005;23:3412-20. Erratum in: J Clin Oncol 2005;23:6281. Harousseau, Jean-Luc [corrected to Avet-Loiseau, Herve].

11. Durie BG, Salmon SE. A clinical staging system for multiple myeloma. Correlation of measured myeloma cell mass with presenting clinical features, response to treatment, and survival. Cancer 1975;36:842-54.

12. Dinse GE, Lagakos SW. Nonparametric estimation of lifetime and disease onset distributions from incomplete observations. Biometrics 1982;38:921-32.

13. Kumar SK, Callander NS, Alsina M, et al. Multiple Myeloma, Version 3.2017, NCCN Clinical Practice Guidelines in Oncology. J Natl Compr Canc Netw 2017;15:230-69.

14. Shipp MA, Abeloff MD, Antman KH, et al. International Consensus Conference on High-Dose Therapy with Hematopoietic Stem Cell Transplantation in Aggressive Non-Hodgkin's Lymphomas: report of the jury. J Clin 
Oncol 1999;17:423-9.

15. Vose JM, Rizzo DJ, Tao-Wu J, et al. Autologous transplantation for diffuse aggressive non-Hodgkin lymphoma in first relapse or second remission. Biol Blood Marrow Transplant 2004;10:116-27.

16. Moore S, Peggs K, Thomson K, et al. Autologous stem cell transplantation remains beneficial for patients relapsing after R-CHOP chemotherapy and who respond to salvage chemotherapy. Br J Haematol 2012;156:142-3.

17. Harousseau JL, Attal M, Avet-Loiseau H. The role of complete response in multiple myeloma. Blood 2009; 114:3139-46.

18. Mukherjee S, Boccaccio D, Sekeres MA, et al. Allogeneic Hematopoietic Cell Transplantation for Myelodysplastic Syndromes: Lingering Uncertainties and Emerging Possibilities. Biol Blood Marrow Transplant 2015;21:412-20.

19. Derman BA, Reiser J, Basu S, et al. Renal Dysfunction and Recovery following Initial Treatment of Newly Diagnosed Multiple Myeloma. Int J Nephrol 2018;2018:4654717.

20. González-Calle V, Dávila J, Escalante F, et al. Bence Jones proteinuria in smoldering multiple myeloma as a predictor marker of progression to symptomatic multiple myeloma. Leukemia 2016;30:2026-31.

21. Richardson PG, Barlogie B, Berenson J, et al. A phase 2 study of bortezomib in relapsed, refractory myeloma. $\mathrm{N}$ Engl J Med 2003;348:2609-17.

22. Grigoreva TA, Tribulovich VG, Garabadzhiu AV, et al. The $26 \mathrm{~S}$ proteasome is a multifaceted target for anticancer therapies. Oncotarget 2015;6:24733-49.

23. Manasanch EE, Orlowski RZ. Proteasome inhibitors in cancer therapy. Nat Rev Clin Oncol 2017;14:417-33.

24. Richardson PG, Sonneveld P, Schuster MW, et al. Bortezomib or high-dose dexamethasone for relapsed multiple myeloma. N Engl J Med 2005;352:2487-98.

25. Durie BG, Miguel JF, Blade J, et al. Clarification of the definition of complete response in multiple myeloma. Leukemia 2015;29:2416-7.

26. Heutte N, Flechtner HH, Mounier N, et al. Quality of life after successful treatment of early-stage Hodgkin's lymphoma: 10-year follow-up of the EORTC-GELA H8 randomised controlled trial. Lancet Oncol 2009;10:1160-70.

27. Guisado-Vasco P, Arranz-Saez R, Canales M, et al. Stage IV and age over 45 years are the only prognostic factors of the International Prognostic Score for the outcome of advanced Hodgkin lymphoma in the Spanish Hodgkin Lymphoma Study Group series. Leuk Lymphoma 2012;53:812-9.
28. Qian F, Fan W, Wei X, et al. Prognostic factors of lymphoma patients after autologous stem cell transplantation. Ann Transplant 2015;20:225-32 .

29. Okada K, Oguchi N, Shinohara K, et al. BUN, Bence Jones protein, and chromosomal aberrations predict survival in multiple myeloma. Rinsho Ketsueki 1997;38:1254-62.

30. Kyle RA, Gertz MA, Witzig TE, et al. Review of 1027 patients with newly diagnosed multiple myeloma. Mayo Clin Proc 2003;78:21-33.

31. Knudsen LM, Hjorth M, Hippe E. Renal failure in multiple myeloma: reversibility and impact on the prognosis. Nordic Myeloma Study Group. Eur J Haematol 2000;65:175-81.

32. Kastritis E, Anagnostopoulos A, Roussou M, et al. Reversibility of renal failure in newly diagnosed multiple myeloma patients treated with high dose dexamethasonecontaining regimens and the impact of novel agents. Haematologica 2007;92:546-9.

33. Czyż A, Łojko-Dankowska A, Matuszak M, et al. Second malignancies after autologous haematopoietic stem cell transplantation following modified BEAM conditioning regimen in patients with Hodgkin lymphoma - characteristics and risk factor analysis. Contemp Oncol (Pozn) 2013;17:200-4.

34. Ali S, Olszewski AJ. Disparate survival and risk of secondary non-Hodgkin lymphoma in histologic subtypes of Hodgkin lymphoma: a population-based study. Leuk Lymphoma 2014;55:1570-7.

35. Knight JM, Moynihan JA, Lyness JM, et al. Peri-transplant psychosocial factors and neutrophil recovery following hematopoietic stem cell transplantation. PLoS One 2014;9:e99778.

36. Hoodin F, Uberti JP, Lynch TJ, et al. Do negative or positive emotions differentially impact mortality after adult stem cell transplant? Bone Marrow Transplant 2006;38:255-64.

37. Molassiotis A, Van Den Akker OB, Milligan DW, et al. Symptom distress, coping style and biological variables as predictors of survival after bone marrow transplantation. J Psychosom Res 1997;42:275-85.

doi: $10.21037 /$ sci.2019.10.05

Cite this article as: Li J, Zhu Y. Survival analysis of multiple myeloma patients after autologous stem cell transplantation. Stem Cell Investig 2019;6:42. 